\section{RESEARCH POSITION}

\section{O} o

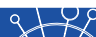

0

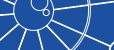

\section{International Center for Young Scientists National Institute for Materials Science (NIMS)}

The International Center for Young Scientists (ICYS) of the National Institute for Materials Science (NIMS) is now seeking a few researchers. Successful applicants are expected to pursue innovative research on broad aspects of materials science using the most advanced facilities in NIMS (http://www.nims.go.jp/eng/index.html). In the ICYS, we offer a special environment that enables young scientists to work independently based on their own ideas and initiatives. All management and scientific discussions will be conducted in English. An annual salary of approximately 5.35 million yen (level of 2017) will be offered depending on qualifications and experience. An additional research grant of 2 million yen per year will be supplied to each ICYS researcher. The initial contract term is two years and may be extended by one more year depending on the person's performance.

All applicants must have obtained a PhD degree within the last ten years. Applicants should submit an application form, including a research proposal to be conducted during the ICYS tenure, CV Header, CV with list of publications and patents (be sure to attach the header), list of DOI of journal publications following our instructions, and reprints of three significant publications, to the ICYS Recruitment Desk by March 29, 2018 JST. The application form and CV header can be downloaded from our website. For more details, please visit our website at:

ICYS Recruitment Desk

National Institute for Materials Science

http://www.nims.go.jp/icys/recruitment/index.htm
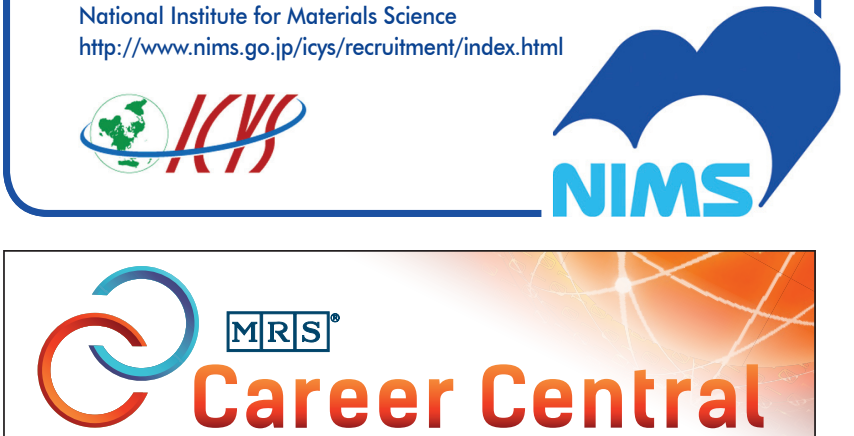

.

MRS Career Central is a one-stop shop for all your career development needs.

Hosted on our Career Central website, the MRS Job Board is FREE to job seekers, serving as the first place to turn to find job openings in the materials science field. The Job Board allows quick and easy access to hundreds of industry-specific job listings, anonymous resume posting and job-alert options to meet your specific needs.

Career Fairs at MRS Spring and Fall Meetings continue to serve as forums to expand your career or your company-providing on-site job interviews, mentoring sessions, resume critiques and mock interviews.

Additional Professional Development sessions or workshops are also offered at MRS Meetings and may include:

- Preparing for Your Next Job Interview

- Negotiating a Job Offer

- Essentials of Getting Your Work Published

- How to Use Your Social Media to Connect with Your Colleagues and the Press

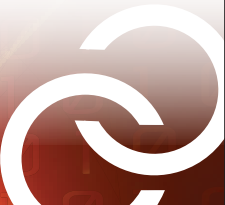

\section{Where should I publish?}
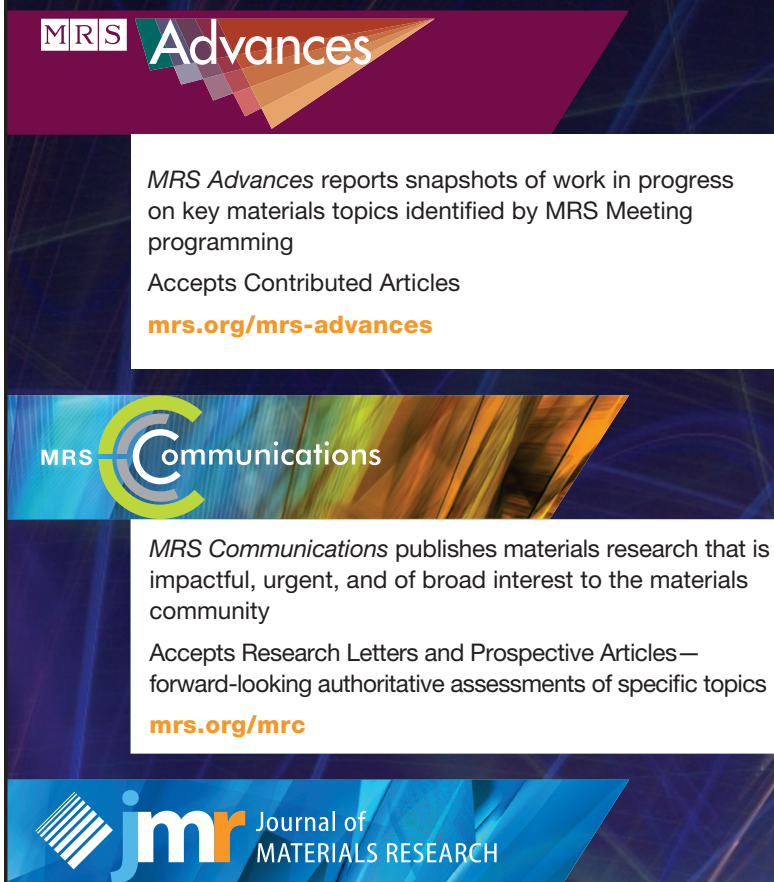

$J M R$ publishes materials research that demonstrates a significant scientific advance or understanding in materials science

Accepts full-length Research Articles and Reviews mrs.org/jmr

\section{MIR ENERGY 96 SUSTAINABILRE}

MRS E\&S addresses broad perspectives in energy and sustainability as they relate to the impact of materials research on society

Accepts Review Articles by proposal or invitation; other article formats may be considered

mrs.org/energy-sustainability-journal

\section{MRSBulletin}

MRS Bulletin provides thematic materials overviews, research news, industry and policy developments, and MRS and materials community news and events Accepts Overview Articles by invitation or proposal mrs.org/bulletin

Five distinct options. One publishing partnership.

\section{$M|R| S$ S}

